\title{
Clinically Important Associations of Pleurodesis Success in Malignant Pleural Effusion; analysis of the TIME1 dataset
}

Rachel M Mercer ${ }^{1,2}$, Jessica Macready ${ }^{1}$, Hannah Jeffries ${ }^{1}$, Nicole Speck ${ }^{3}$, Nikolaos I Kanellakis ${ }^{1,4}$, Nick A. Maskell ${ }^{5}$, Justin Pepperell ${ }^{6}$, Tarek Saba ${ }^{7}$, Alex West $^{8}$, Nabeel Ali ${ }^{9}$, John P Corcoran ${ }^{1,2}$, Robert J Hallifax $^{1,2}$, loannis Psallidas ${ }^{1,2}$, Rachelle Asciak ${ }^{1,2}$, Maged Hassan ${ }^{1,2,10}$, Robert F Miller ${ }^{11}$, Najib M Rahman $^{1,2,12}$.

\footnotetext{
${ }^{1}$ University of Oxford Respiratory Trials Unit, Churchill Hospital, Oxford, UK

${ }^{2}$ Oxford Centre for Respiratory Medicine, Oxford University Hospitals NHS Trust, Oxford, UK

${ }^{3}$ University of Zurich, Zurich, Switzerland

${ }^{4}$ Laboratory of Pleural and Lung Cancer Translational Research, Nuffield Department of Medicine, University of Oxford

${ }^{5}$ Academic Respiratory Unit, Bristol Medical School, Southmead Hospital, University of Bristol, Bristol, UK

${ }^{6}$ Somerset Lung Centre, Musgrove Park Hospital, Taunton, UK

${ }^{7}$ Blackpool Teaching Hospitals NHS Foundation Trust, Blackpool, UK

${ }^{8}$ Guys and St Thomas Hospital, London, UK

${ }^{9}$ King's Mill Hospital, Mansfield, UK

${ }^{10}$ Chest Diseases Department, Faculty of Medicine, Alexandria University, Egypt

${ }^{11}$ Institute for Global Health, University College London, London, UK

${ }^{12}$ NIHR Oxford Biomedical Research Centre, University of Oxford, Oxford, UK
}

\section{Corresponding Author:}

Dr Rachel M Mercer, University of Oxford Respiratory Trials Unit, Churchill Hospital, Oxford, UK OX3 7LE

Email: Rachel.mercer@nhs.net; Phone: +44(0)1865 225205; Fax: +44(0)1865 857109

\section{Short title}

Predictors of Pleurodesis Success

\section{Key Words:}

Malignant pleural effusion; mesothelioma; chest tube; pleurodesis; thoracoscopy

Word Count: 2480

\section{Authors Contribution Statement:}

RMM was responsible for initial draft preparation and revision. NAM, JP, TS, AW, NA, RFM, IP and NMR were authors of the original TIME1 paper. All authors were responsible for reviewing and approving the final manuscript. RMM and NMR are responsible for the overall content as guarantors.

\section{Conflict of Interests Statement:}

None of the authors report any conflict of interests relevant to the production of this article.

\section{Funding:}

No external funding was sought or required in relation to analysis of TIME1 data, its interpretation, and in the writing of this manuscript. RFM is supported by CNWL and Royal Free London NHS Foundation Trusts. NMR is supported by the NIHR Oxford Biomedical Research Centre. The TIME1 trial was funded by the Medical Research Council UK. 
Data Sharing:

Deidentified participant data may be shared with collaborators on application to the corresponding author of the original trial. No other data will be shared. 


\section{Summary at a glance}

Inflammation, as evidenced by a greater rise in C-reactive protein levels, is associated with pleurodesis success but there is no association between success and degree of pain after pleurodesis. Patients with mesothelioma are more likely to experience pleurodesis failure but the mechanisms for this are unclear. 


\section{Abstract}

Background

Chemical pleurodesis is undertaken for patients with a malignant pleural effusion with a published success rate of around $80 \%$. It has been postulated that inflammation is key in achieving successful pleural symphysis, as evidenced by higher amounts of pain or detected inflammatory response. Patients with mesothelioma are postulated to have a lower rate of successful pleurodesis due to lack of normal pleural tissue enabling an inflammatory response.

\section{Methods}

The TIME1 trial dataset, in which pleurodesis success and pain were co-primary outcome measures, was used to address a number of these assumptions. Pain score, systemic inflammatory parameters as a marker of pleural inflammation and cancer type were analysed in relation to pleurodesis success.

Results

285 patients were included with an overall success rate of $84.1 \%$. There was a significantly higher rise in C-Reactive Protein (CRP) in the Pleurodesis Success group compared with the Pleurodesis Failure group (mean difference $19.2,95 \% \mathrm{Cl}$ of the difference 6.2 to $32.0, p=0.004$ ) but no significant change in White Cell Count. There was no significant difference in pain scores or analgesia requirements between the groups. Patients with mesothelioma had a lower rate of pleurodesis success than non-mesothelioma patients ( $73.3 \%$ versus $84.9 \%, \chi^{2}=5.1, p=0.023$ ).

\section{Conclusion}

Change in CRP during pleurodesis is associated with successful pleurodesis but higher levels of pain are not associated. Mesothelioma appears less likely to successfully pleurodese than other 
malignancies, but there is still a significant rise in systemic inflammatory markers. The mechanisms of these findings are unclear but warrants further investigation. 


\section{Introduction}

Malignant pleural effusion (MPE) is a common complication of advanced malignancy, has a poor prognosis and a significant impact on quality of life (1). Historically, the most common treatment and the one with the largest evidence base is chemical pleurodesis using sterile talc, although in recent years indwelling pleural catheters have become more popular. A meta-analysis of 18 studies which used sterile talc for pleurodesis reported success rates between $76 \%$ and $82 \%$ (2). Talc pleurodesis often requires hospitalisation for up to a week, and for patients in whom this intervention fails, further (inpatient and ambulatory care) procedures are needed.

Inflammation is thought to be a key factor in achieving a successful pleurodesis. Talc is known to cause inflammation and it is thought that the intra-pleural inflammatory response is key to achieving pleural symphysis (3) by the production of adhesions after inflammation. It has been theorised that pain is associated with pleurodesis success (as this signifies pleural inflammation) but there is little evidence to support this. A study of tetracycline pleurodesis showed the opposite in a small number of patients (4). Patients undergoing pleurodesis experience varying degrees of pain related to the procedure, but the reasons for this are unclear.

Case series suggest that MPE associated with mesothelioma has lower rates of pleurodesis success in comparison with MPE from other pleural malignancy (6). Several explanations have been suggested, including the prevalence of unexpandable lung and increased intra-thoracic tumour bulk, which potentially reduces the residual "normal" pleural surface area thought to be necessary for pleurodesis (3). Normal mesothelial cells are involved in the activation of inflammatory pathways leading to fibrin formation and adhesions which result in pleural symphysis. Animal studies demonstrate that intrapleural instillation of talc causes inflammation which leads to pleurodesis (7, 8); thus, when there is little remaining normal pleural tissue, rates of successful pleurodesis may 
theoretically be reduced. A study which used a scoring system to assess the degree of pleural involvement showed that higher tumour burden was negatively correlated with pleurodesis success, as was type of tumour (9).

This study therefore aimed to explore the hypothesis that inflammation, as signified by pain and a rise in systemic inflammatory markers, is related to pleurodesis success, and that mesothelioma related MPE is associated with higher pleurodesis failure, using prospectively collected data from the TIME1 trial (10). 


\section{Methods}

Data set

This retrospective analysis is based on data from the prospectively collected TIME1 trial data. All study participants provided written informed consent for the randomised controlled trial and approval was given to use the deidentified dataset for further analysis. The TIME1 trial (10) enrolled 320 patients with MPE who underwent talc pleurodesis (either at thoracoscopy, or with talc slurry after insertion of an intercostal chest drain). Patients were randomised to either receive a $24 \mathrm{~F}$ or $12 \mathrm{~F}$ chest drain and either opiate or non-steroidal anti-inflammatory medication (NSAIDs) in a $2 \times 2$ factorial design, with primary outcomes being pleurodesis success at three months and pain. Analysis was performed using the group as a whole as the analgesia arms were concluded to have similar efficacy, and while there was a small difference in pain scores between the $12 \mathrm{~F}$ and $24 \mathrm{~F}$ chest drains this did not meet the criteria for clinical significance (13). Important results were also reanalysed in the thoracoscopy and non-thoracoscopy arms separately to assess validity of any results.

Enrolled patients required a clinically confident diagnosis of a malignant pleural effusion, and exclusions included lymphoma, small cell lung cancer, increased risk of bleeding, and sensitivity to opiates / NSAIDs. Full inclusion and exclusion criteria are available in the published manuscript (10). Pain was measured with a validated tool (100mm Visual Analogue Score: VAS), and pleurodesis failure was defined on pre-hoc objective criteria (radiological recurrence requiring further pleural intervention) (10-12).

\section{Outcomes and variables}

The primary outcomes of pleurodesis success was defined as no requirement for further pleural intervention on the ipsilateral side for breathlessness in the three months after pleurodesis (10), and objective scoring of chest x-rays in cases where intervention was not appropriate. Variables with potential association with pleurodesis success were investigated using this dataset. 
Potential factors associated with pleurodesis were tested using data described below; with all definitions established prior to analysis:

1. Changes in systemic inflammatory markers (C-reactive protein (CRP) and white cell count (WCC), measured on the day of pleurodesis (Day 0 ) and one day after (Day 1)).

2. Changes in pain score (measured at baseline and four times per day, using $100 \mathrm{~mm}$ VAS). The average of the available data for each 24-hour period was used, with scores used over the first 48-hour period only, as inflammation from pleurodesis is likely to have occurred over that time period.

3. Underlying malignancy (mesothelioma versus other pathological cancer types; those without a definite oncological diagnosis were excluded from the mesothelioma analysis)

\section{Statistical Analysis}

Data were assessed for normality, with normally distributed data analysed using $t$ tests and nonnormally distributed data analysed using the Mann Whitney $U$ test. For normally distributed data, outliers (>3 Standard Deviations: SD from the mean) were excluded. Proportional data was analysed using the $\chi 2$ test where sufficient events occurred. For normally distributed paired data a paired $\mathrm{t}$ test was used, for non-normally distributed data a Wilcoxon signed rank test was used. Missing data was not imputed. 


\section{Results}

Data quality

Of 320 patients enrolled, data quality was insufficient in two patients. Outcomes concerning pleurodesis were not available for 21 patients. Seventeen patients, all in the non-thoracoscopy arm, did not receive talc which due to drain displacement or re-siting $(n=6)$. All of these patients (pleurodesis outcome not available, pleurodesis not conducted) were excluded, with the analysis therefore performed in a total of 285 patients. (Table 1 ).

\section{Pleurodesis Success}

Overall pleurodesis success rate at three months was $232 / 285=81.4 \%$. The pleurodesis success rate was $33 / 42=78.6 \%$ in the $12 \mathrm{~F}$ group and $199 / 243=81.9 \%$ in the $24 \mathrm{~F}$ group. Patients were categorised either as having successful pleurodesis (Pleurodesis Success group) or failed pleurodesis (Pleurodesis Failure group).

\section{Inflammatory Parameters}

Three patients with outlying results were excluded (one from CRP and two from WCC analysis). Changes in WCC and CRP were normally distributed, but baseline values for each group were nonnormally distributed.

There was no significant difference in baseline WCC between Pleurodesis Success and Pleurodesis Failure groups. The WCC significantly increased in response to pleurodesis (comparing Day 0 with Day 1 ) in both Pleurodesis Success and Failure groups ( $p<0.001$ for both groups, Mann Whitney) (Table 2). The mean WCC change was higher in the Pleurodesis Success group $\left(2.35 \times 10^{9} / \mathrm{L}, \mathrm{SD} 2.94\right.$, $95 \% \mathrm{Cl} 1.92$ to 2.78$)$ than in the Pleurodesis Failure group (1.79x10\%/L, SD $2.44,95 \% \mathrm{Cl} 1.00$ to 2.58$)$, with a mean difference of 0.56 , but this did not reach statistical significance $(95 \% \mathrm{Cl}$ of the difference -0.33 to $1.45, p=0.214)$. 
There was no significant difference in baseline CRP between Pleurodesis Success and Failure groups. The CRP significantly increased from Day 0 to Day 1 in both the Pleurodesis Success and Failure groups ( $p<0.001$ for both groups, Mann Whitney) (Table 2). Mean CRP change was higher in the Pleurodesis Success group (46.2 mg/L, SD $48.3,95 \% \mathrm{Cl} 38.5$ to 53.9 ) than in the Pleurodesis Failure group (27.1mg/L, SD $32.5,95 \% \mathrm{Cl} 16.5$ to 37.6 ) (mean difference $19.2,95 \% \mathrm{Cl}$ of the difference 6.2 to 32.0, $p=0.004$ ) (Figure 1). The mean CRP change was higher in the Pleurodesis Success group in both the thoracoscopy and non-thoracoscopy arms but only maintained statistical significance in the thoracoscopy arm (Table 3).

Incremental cut-offs of CRP rise were explored to assess potential association with pleurodesis success. Using a CRP rise of $\geq 30 \mathrm{mg} / \mathrm{L}, 84.7 \%$ of patients in the Pleurodesis Success group met this criterion compared with $72 \%$ in the Pleurodesis Failure group $\left(\chi^{2}=4.62,1 \mathrm{df}, \mathrm{p}=0.032\right)$.

Pain

The median VAS score at baseline was $3.8 \mathrm{~mm}$ (IQR 1.0 to 11.8 ). The median of the average VAS scores over the first 24 hours for the entire cohort was $23.4 \mathrm{~mm}$ (IQR 8.8 to $37.8 \mathrm{~mm}$ ) and between 24 - 48 hours was $14.4 \mathrm{~mm}$ (IQR 4.8 to $28.5 \mathrm{~mm}$ ).

The average VAS score over the first 24 hours was $23.6 \mathrm{~mm}$ (IQR 9.9 to 40.1 ) for the Pleurodesis Success group and $21.4 \mathrm{~mm}$ (IQR 5.8 to $36.5 \mathrm{~mm}$ ) for the Pleurodesis Failure group ( $p=0.42$ ). Over the subsequent 24 hours, median VAS was $14.5 \mathrm{~mm}$ (IQR 4.7 to $26.7 \mathrm{~mm}$ ) for the Pleurodesis Success group and $14.2 \mathrm{~mm}$ (IQR 5.2 to $31.2 \mathrm{~mm}$ ) for the Pleurodesis Failure group $(\mathrm{p}=0.91)$. Median change in VAS between baseline and the first 24 hours after pleurodesis was lower in the Pleurodesis Success group ( $11.7 \mathrm{~mm}$, IQR 1.3 to $25.2 \mathrm{~mm}$ ) than in the Pleurodesis Failure group $(13.5 \mathrm{~mm}$ (0.3 to 
$24.9 \mathrm{~mm})$, but this was not statistically significant $(p=0.65)$. There was no significant difference when the VAS scores were analysed in the thoracoscopy and non-thoracoscopy arms separately (Table 4).

The majority of patients did not require any additional doses of analgesia, in addition to the regular analgesia prescribed, in either the Pleurodesis Success or Failure groups: median additional doses $=0$, IQR 0 to 1 for both groups $(p=0.32)$.

\section{Mesothelioma}

Patients with mesothelioma had significantly lower overall pleurodesis success rates than nonmesothelioma ( $73.3 \%$ versus $84.9 \%, \chi 2=5.1,1 \mathrm{df}, \mathrm{p}=0.023)$. However, unexpandable lung was more common in those with mesothelioma (19.5\%) compared with those with non-mesothelioma (12.9\%), although this did not reach statistical significance $\left(\chi^{2}=1.84,1 \mathrm{df}, \mathrm{p}=0.18\right)$. When patients with unexpandable lung were excluded from analysis ( 38 with trapped lung, 28 with no data), 87 patients with mesothelioma and 139 non-mesothelioma remained; in these patients there was a nonsignificant difference in rates of pleurodesis success in mesothelioma patients (74.7\%) compared with those with other types of cancer $(84.9 \%), \chi^{2}=3.60,1 d f, p=0.058$.

Despite a lower pleurodesis success rate in patients with mesothelioma, the degree of systemic inflammation in response to talc was higher than that seen in those with non-mesothelioma causes (CRP change in those with mesothelioma $58.9 \mathrm{mg} / \mathrm{L}$, SD $42.6,95 \% \mathrm{Cl} 49.2$ to 68.6 , versus $26.8 \mathrm{mg} / \mathrm{L}$, SD 43.9, $95 \% \mathrm{Cl} 17.9$ to 35.7 in those with non-mesothelioma related MPE. Mean difference in CRP $32.1 \mathrm{mg} / \mathrm{L}, 95 \% \mathrm{Cl}$ of the difference 19.1 to $45.2, \mathrm{p}<0.001)$. 


\section{Discussion}

This analysis supports the hypothesis that higher levels of systemic inflammation, using serum CRP as a marker, are related to pleurodesis success in patients with MPE not due to mesothelioma. Patients with MPE caused by mesothelioma appear less likely to achieve successful pleurodesis, despite evidence of higher systemic inflammatory response to talc. There is no evidence to support the dictum that higher levels of pain are associated with pleurodesis success.

\section{The effect of Inflammation}

An assumption has been made that serum CRP levels are a representative assessment of inflammation within the pleural space. Although we demonstrated a statistically significant difference in the change in CRP between the groups, there was no specific cut off which could be used to predict pleurodesis success or was clinically applicable. The change did not remain significant in the non-thoracoscopy arm but this was a much smaller group and it is also important to note that there was already a difference in CRP levels before pleurodesis was attempted which could represent inflammation which had been caused by the prior chest tube insertion. Likewise, there was no signal from baseline values which aids the clinician in decision-making regarding whether to attempt pleurodesis or pursue other treatment options. However, these data support the premise that increased (systemic) inflammation is associated with higher pleurodesis success, and there may be specific localised immune responses associated with pleurodesis success. This hypothesis requires specific assessment in the pleural space and may have implications for the use of steroids during pleurodesis. It is noteworthy that the TIME1 trial clearly demonstrated that NSAIDs have no effect on pleurodesis success used in the short term.

\section{VAS pain scores}

This analysis verifies the clinical observation that pleurodesis causes significant pain, as the established minimal clinically significant threshold of $13 \mathrm{~mm}$ for the VAS pain score (13) was reached 
between enrolment and 24 hours post pleurodesis. Baseline and average VAS scores over 24 hours in the success and failure groups were similar, demonstrating that the clinical assumption that higher levels of pain predict pleurodesis success is not accurate. The pain scores were higher in the thoracoscopy arm but these patients underwent drain insertion and pleurodesis in the same procedure whereas there was an interval between the two in the non-thoracoscopy arm, so direct comparison would not be accurate. In the original TIME1 analysis there was no difference between the groups with regards to the effectiveness of NSAIDs versus opiates, and thus an assumption has been made that the baseline analgesic effects between the groups were equivalent.

\section{Mesothelioma}

The rates of successful pleurodesis in mesothelioma patients was significantly lower than that seen in other malignancies. There were higher rates of unexpandable lung in those with mesothelioma, but this did not reach statistical significance, likely due to small numbers. Rates of unexpandable lung of between $22 \%(14)$ and $41 \%$ have been reported (15) in small series of less than 200 patients in total, and a high proportion of these were due to mesothelioma. The rates of unexpandable lung in those with mesothelioma in this study are likely to underestimate the true prevalence, as patients with known unexpandable lung would not be offered pleurodesis. When patients with unexpandable lung were excluded from the pleurodesis analysis there was no longer a significant difference between the groups, but again this may be due to the sample size.

Evidence to support the hypothesis that reduced inflammation due to the reduced surface area of normal pleura in patients with mesothelioma was not evident in our study (3). Rates of inflammation, using change in CRP as a surrogate marker, were in fact higher in patients with MPE associated with mesothelioma than in those with other cancers, despite a lower rate of pleurodesis success. This is an interesting finding and we postulate that this may be due to a more intense inflammatory process on talc administration in those with mesothelioma, but that additionally there 
is insufficient remaining normal visceral pleural surface to permit pleural symphysis. The precise relationship between intensity of initial pleural inflammatory response and final pleural symphysis requires further study.

\section{Conclusions}

This study suggests those patients with a greater inflammatory response, as signified by rise in CRP, are more likely to have a successful pleurodesis. This information is unlikely to change clinical decision making but could provide a focus for further translational research, which has already started being undertaken in this area (16). Despite good background analgesia, pleurodesis causes significant pain, although the degree of pain does not appear to affect pleurodesis success. When new pleurodesis agents are developed, those which promote inflammation without causing pain will have a clear utility in management of MPE. Patients with MPE due to mesothelioma appear to behave differently in response to pleurodesis compared with those with MPE from other types of pleural cancer and should be counselled as such when discussing therapeutic options. 


\section{$\underline{\text { References }}$}

1. Roberts ME, Neville E, Berrisford RG, Antunes G, Ali NJ. Management of a malignant pleural effusion: British Thoracic Society Pleural Disease Guideline 2010. Thorax. 2010;65 Suppl 2:ii32-40. 2. Xia H, Wang XJ, Zhou Q, Shi HZ, Tong ZH. Efficacy and safety of talc pleurodesis for malignant pleural effusion: a meta-analysis. PloS One. 2014;9(1):e87060.

3. Rodriguez-Panadero F, Montes-Worboys A. Mechanisms of pleurodesis. Respiration. 2012;83(2):91-8.

4. Robinson LA, Fleming WH, Galbraith TA. Intrapleural doxycycline control of malignant pleural effusions. Ann Thorac Surg. 1993;55(5):1115-21; discussion 21-2.

5. Aydogmus U, Ozdemir S, Cansever L, Sonmezoglu Y, Kocaturk Cl, Bedirhan MA. Bedside talc pleurodesis for malignant pleural effusion: factors affecting success. Ann Surg Oncol. 2009;16(3):745-50.

6. Ak G, Metintaş M, Yildirim H, Metintaş S, Dündar E, Erginel S, et al. Pleurodesis in follow-up and treatment of malignant pleural mesothelioma patients. Tuberk Toraks. 2009;57:22-31.

7. Xie C, Teixeira LR, McGovern JP, Light RW. Systemic corticosteroids decrease the effectiveness of talc pleurodesis. Am J Resp Crit Care Med. 1998;157(5 Pt 1):1441-4.

8. Kennedy L, Harley RA, Sahn SA, Strange C. Talc slurry pleurodesis. Pleural fluid and histologic analysis. Chest. 1995;107(6):1707-12.

9. Bielsa S, Hernández P, Rodriguez-Panadero F, Taberner T, Salud A, Porcel JM. Tumor Type Influences the Effectiveness of Pleurodesis in Malignant Effusions. Lung. 2011;189(2):151-5.

10. Rahman NM, Pepperell J, Rehal S, Saba T, Tang A, Ali N, et al. Effect of Opioids vs NSAIDs and Larger vs Smaller Chest Tube Size on Pain Control and Pleurodesis Efficacy Among Patients With Malignant Pleural Effusion: The TIME1 Randomized Clinical Trial. JAMA. 2015;314(24):2641-53. 
11. Davies HE, Mishra EK, Kahan BC, Wrightson JM, Stanton AE, Guhan A, et al. Effect of an indwelling pleural catheter vs chest tube and talc pleurodesis for relieving dyspnea in patients with malignant pleural effusion: the TIME2 randomized controlled trial. JAMA. 2012;307(22):2383-9.

12. Mishra EK, Clive AO, Wills GH, et al. Randomised Controlled Trial of Urokinase versus Placebo for Non-draining Malignant Pleural Effusion. Am J Respir Crit Care Med. 2018;197:502-508. 13. Gallagher EJ, Liebman M, Bijur PE. Prospective validation of clinically important changes in pain severity measured on a visual analog scale. Annal Emerg Med. 2001;38(6):633-8.

14. Aujayeb A, Parker S, Bourke S, Miller J, Cooper D. A review of a pleural service. J R Coll Physicians Edinb. 2016 Mar;46:26-31

15. Qureshi RA, Collinson SL, Powell RJ, Froeschle PO, Berrisford RG. Management of malignant pleural effusion associated with trapped lung syndrome. Asian Cardiovasc Thorac Ann. 2008;16:1203.

16. Psallidas I, Kanellakis NI, Gerry S, Thézénas ML, Charles PD, Samsonova A, et al. Development and validation of response markers to predict survival and pleurodesis success in patients with malignant pleural effusion (PROMISE): a multicohort analysis. Lancet Oncol. 2018;19:930-939. 
Table 1: Baseline characteristics according to pleurodesis outcome.

\begin{tabular}{|c|c|c|c|c|}
\hline & All $(n=285)$ & $\begin{array}{c}\text { Pleurodesis } \\
\text { success } \\
(n=232)\end{array}$ & $\begin{array}{l}\text { Pleurodesis } \\
\text { Failure } \\
(n=53)\end{array}$ & Significance \\
\hline Age, years & $\begin{array}{c}72 \\
(64.5-79.5)\end{array}$ & $\begin{array}{c}72 \\
(64-79)\end{array}$ & $\begin{array}{c}73 \\
(65-80)\end{array}$ & $\mathrm{p}=0.57$ (Mann Whitney) \\
\hline Male, n (\%) & $\begin{array}{c}184 \\
(64.6 \%) \\
\end{array}$ & $\begin{array}{c}145 \\
(62.5 \%) \\
\end{array}$ & $\begin{array}{c}39 \\
(73.6 \%) \\
\end{array}$ & $\begin{array}{c}\chi 2=2.3,1 d f \\
p=0.13\end{array}$ \\
\hline $\begin{array}{c}\text { Thoracoscopy, } \\
\text { n (\%) }\end{array}$ & $\begin{array}{c}196 \\
(68.8 \%)\end{array}$ & $\begin{array}{c}162 \\
(69.8 \%) \\
\end{array}$ & $\begin{array}{c}34 \\
(64.2 \%) \\
\end{array}$ & $\begin{array}{c}\chi 2=0.60,1 d f, \\
p=0.42\end{array}$ \\
\hline $\begin{array}{c}\text { 24F drain, } \\
\text { n (\%) }\end{array}$ & $\begin{array}{c}243 \\
(85.3 \%)\end{array}$ & $\begin{array}{c}199 \\
(85.8 \%)\end{array}$ & $\begin{array}{c}44 \\
(83.0 \%)\end{array}$ & $\begin{array}{c}\chi^{2}=0.26,1 d f \\
p=0.61\end{array}$ \\
\hline $\begin{array}{c}\text { Unexpandable } \\
\text { lung, n (\%) }\end{array}$ & $\begin{array}{c}38(14.8 \%) \\
n=257\end{array}$ & $\begin{array}{c}26(12.3 \%) \\
n=211\end{array}$ & $\begin{array}{c}12(26.1 \%) \\
n=46\end{array}$ & $\begin{array}{c}\chi 2=5.68,1 d f \\
p=0.017\end{array}$ \\
\hline
\end{tabular}

Data for continuous variables is presented as median (IQR) and for discrete variables as frequency (\%). 
Table 2: Inflammatory markers according to pleurodesis outcome.

\begin{tabular}{|c|c|c|c|c|}
\hline & $\mathbf{n}$ & Pleurodesis Success & Pleurodesis Failure & P Value \\
\hline WCC, (10 $/ \mathbf{L})$, Day 0 & 259 & $8.20(6.68-10.10)$ & $8.43(7.34-10.90)$ & 0.28 \\
\hline WCC, (10 $/ \mathbf{L})$, Day 1 & 233 & $10.43(8.45-13.49)$ & $11.01(8.81-12.65)$ & 0.75 \\
\hline CRP, (mg/mL), Day 0 & 223 & $34.0(13.0-83.0)$ & $38.0(11.0-79.0)$ & 0.80 \\
\hline CRP, (mg/mL), Day 1 & 219 & $95.0(58.3-136.0)$ & $77.0(48.5-107.5)$ & 0.065 \\
\hline
\end{tabular}

Data are presented as median (IQR). 
Table 3. CRP values $(\mathrm{mg} / \mathrm{mL})$ according to pleurodesis outcome

\begin{tabular}{|c|c|c|c|c|}
\hline & $\mathbf{n}$ & Pleurodesis Success & Pleurodesis Failure & P Value \\
\hline Thoracoscopy arm, Day 0 & 148 & $25.5(7.0-56.25)$ & $27.5(8.5-79.0)$ & 0.62 \\
\hline Thoracoscopy arm, Day 1 & 152 & $98.0(64.0-135.0)$ & $74.5(51.0-107.75)$ & 0.10 \\
\hline $\begin{array}{c}\text { Thoracoscopy arm, } \\
\text { Change }\end{array}$ & 129 & $61.75(44.53)$ & $33.67(29.75)$ & $<0.001$ \\
\hline $\begin{array}{c}\text { Non-thoracoscopy arm } \\
\text { Day 0 }\end{array}$ & 75 & $57.0(22.75-141.75)$ & $48.0(19.5-103.0)$ & 0.33 \\
\hline $\begin{array}{c}\text { Non-thoracoscopy arm } \\
\text { Day 1 }\end{array}$ & 67 & $87.5(53.5-149.25)$ & $79.0(41.5-107.5)$ & 0.41 \\
\hline $\begin{array}{c}\text { Non-thoracoscopy arm } \\
\text { Change }\end{array}$ & 63 & $15.1(39.9)$ & $12.17(34.6)$ & 0.80 \\
\hline
\end{tabular}

Data are presented as median (IQR) for Day 0 and Day 1 statistics and mean (SD) for CRP Change.

Day 0 represents the day pleurodesis was undertaken. 
Table 4. 100mm VAS scores in Thoracoscopy and Non-thoracoscopy arms

\begin{tabular}{|c|c|c|c|c|}
\hline $\begin{array}{c}\text { Thoracoscopy arm, } \\
\text { Baseline }\end{array}$ & $\mathbf{n}$ & Pleurodesis Success & Pleurodesis Failure & P Value \\
\hline $\begin{array}{c}\text { Thoracoscopy arm, Day } 1 \\
\text { post-pleurodesis }\end{array}$ & 188 & $25.0(1.0-10.15)$ & $3.5(1.08-7.38)$ & 0.81 \\
\hline $\begin{array}{c}\text { Thoracoscopy arm, } \\
\text { Change from baseline }\end{array}$ & 181 & $17.01(23.74)$ & $14.12(22.47)$ & 0.52 \\
\hline $\begin{array}{c}\text { Non- thoracoscopy arm } \\
\text { Baseline }\end{array}$ & 87 & $5.65(2.0-16.05)$ & $8.5(1.5-13.0)$ & 0.98 \\
\hline $\begin{array}{c}\text { Non- thoracoscopy arm } \\
\text { Day 1 post-pleurodesis }\end{array}$ & 72 & $14.31(5.81-32.20)$ & $15.54(3.52-36.64)$ & 0.83 \\
\hline $\begin{array}{c}\text { Non- thoracoscopy arm, } \\
\text { Change from baseline }\end{array}$ & 71 & $8.98(23.57)$ & $6.19(25.56)$ & 0.70 \\
\hline
\end{tabular}

VAS scores presented as average from the number of values recorded over 24 hours. Presented as median (IQR) for Baseline and Day 1 post pleurodesis and mean (SD) for Change from baseline. 
Figure 1: Mean change in CRP Comparing Pleurodesis Success and Pleurodesis Failure groups.

\section{Mean CRP change}

Error bars marking $95 \% \mathrm{Cl}$

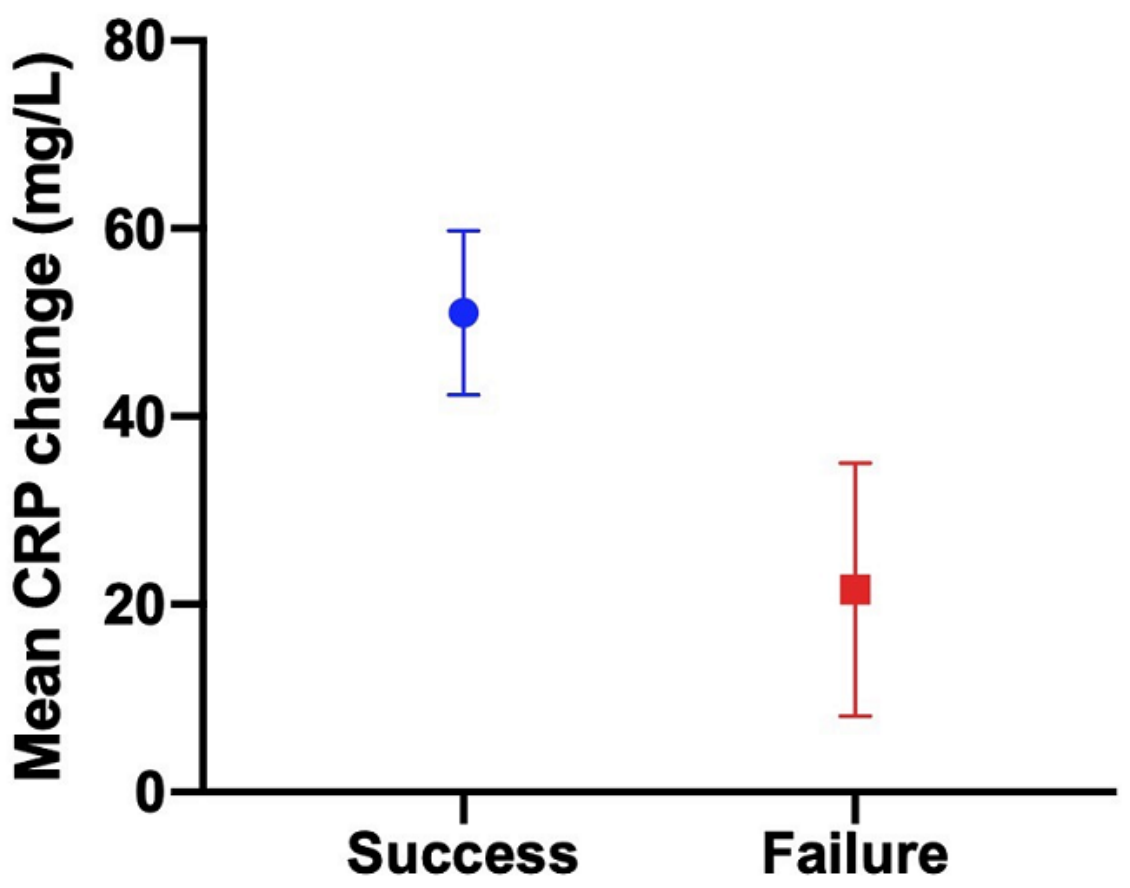

Pleurodesis 